\title{
La función reparadora en ejercicios de memoria histórica
}

\section{The restorative function in historical memory exercises}

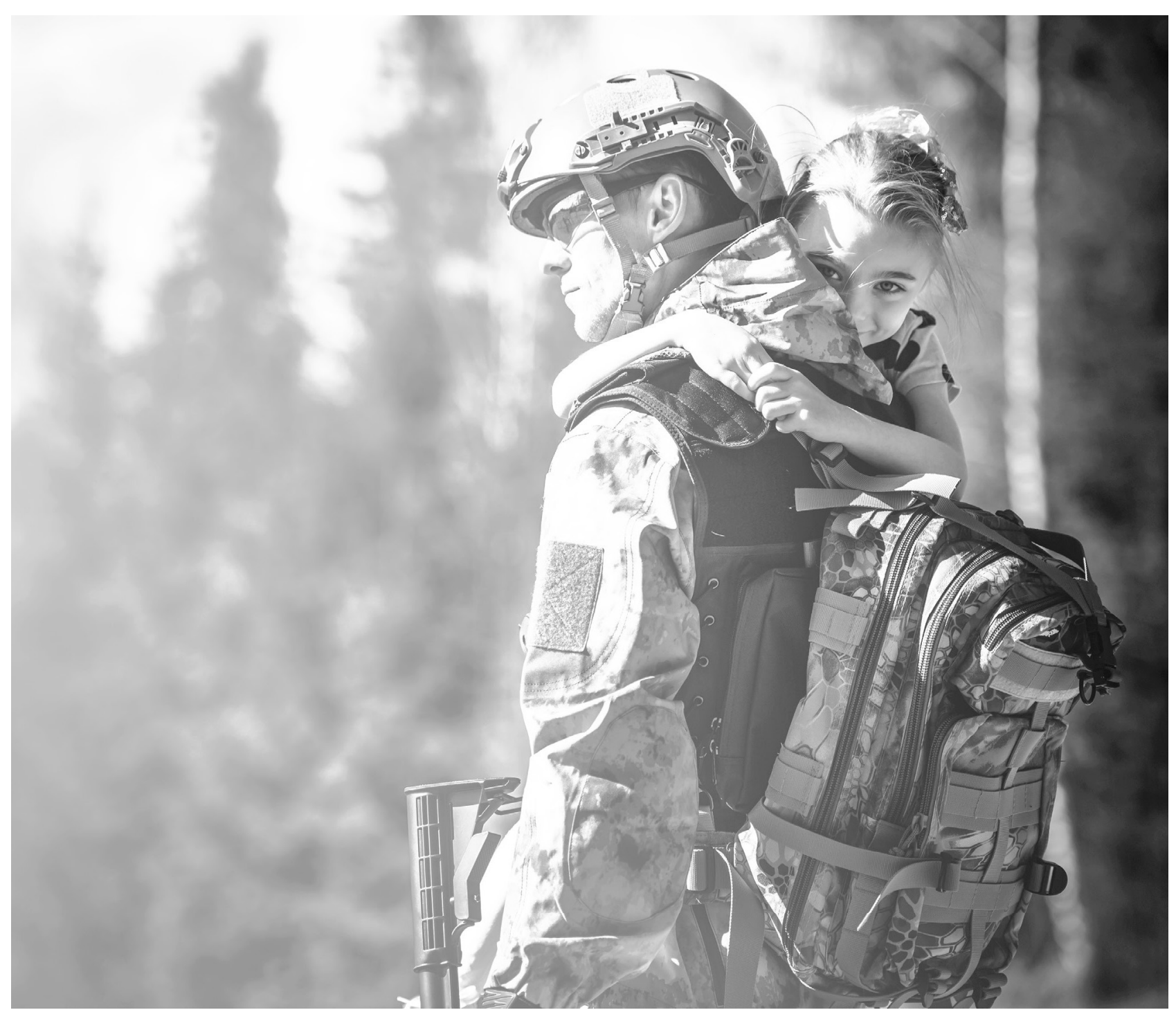




\title{
La función reparadora en ejercicios de memoria histórica ${ }^{1}$ The restorative function in historical memory exercises
}

\author{
Roberto Eduardo Reyes-Gámez²
}

Artículo recibido en enero 16 de 2020; artículo aceptado en marzo 24 de 2020

Este artículo puede compartirse bajo la Licencia Creative Commons Atribución-NoComercial-Compartirlgual 4.0 Internacional y se referencia usando el siguiente formato: Reyes-Gámez, R. E. (2020). La función reparadora en ejercicios de memoria histórica. I+D Revista de Investigaciones, 15 (2), 38-48. DOI: https://doi.org/10.33304/revinv.v15n2-2020004

\section{Resumen}

La memoria histórica en Colombia, fragmentada por la violencia política y afectada social y psicológicamente, termina volviéndose una herramienta terapéutica que, aplicada socialmente, es fundamental para aprender las lecciones que el conflicto armado ha dejado, y para superar las consecuencias que han quedado de este fenómeno. Este documento de análisis y revisión de investigaciones previas y contrastadas in situ, a través de las acciones de memoria histórica adelantadas por entidades como el Centro Nacional de Memoria Histórica y la Comisión Nacional de Reparación y Reconciliación, pretende mostrar las consecuencias positivas y reparadoras de un ejercicio de memoria en población víctima y en población excombatiente. La importancia de este trabajo redunda en un mejor aprovechamiento de la memoria histórica como elemento reparador y, por ende, sanador de los efectos de fenómenos como el conflicto político armado.

Palabras clave: Memoria, narrativas, reparación, terapia.

\section{Abstract}

The historical memory in Colombia, fragmented by political violence and affected socially and psychologically, ends up becoming a therapeutic tool that, applied socially, is essential to learn the lessons that the armed conflict has left and to overcome the consequences that have remained from this phenomenon. This paper analyzes and reviews previous investigations verified in situ, through the actions of historical memory carried out by entities such as the Centro Nacional de Memoria Histórica y la Comisión Nacional de Reparación y Reconciliación, and aims to show the positive and restorative consequences of a memory exercise, in victim and ex-combatant populations. The importance of this task results in a better use of historical memory, as a repairing element and, therefore, a healer from the effects of phenomena such as armed political conflict.

\footnotetext{
'Artículo de revisión, de enfoque cualitativo, resultado de un proyecto de investigación-intervención culminado, denominado "Caja de herramientas para la atención en ejercicios de memoria", desarrollado por el equipo psicosocial del Centro Nacional de Memoria Histórica (CNMH) y la Organización Internacional para las Migraciones (OIM), perteneciente al área de ciencias sociales, subárea de psicología, y desarrollado en las ciudades de Bogotá, Cali, Medellín, Valledupar, Montería, Santa Marta, Villavicencio, Apartadó y Puerto Boyacá. Dirección: calle 35 n. 5 5-81. PBX: (571) 796 5060. Fecha de inicio: 2015. Fecha de finalización: 2018.

${ }^{2}$ Psicólogo especialista en Paz y Desarrollo Territorial y especialista en Gestión Humana. Docente de investigación en la Escuela de Cadetes de Policía General Santander. Profesional psicosocial, líder de la estrategia psicosocial e investigador de la Dirección de Acuerdos de la Verdad del Centro Nacional de Memoria Histórica (Bogotá, Colombia). Dirección: calle 35 n. ${ }^{\circ}$ 5-81. PBX: (571) 796 5060. ORCID ID: https://orcid.org/0000-00027185-3866. Correo electrónico institucional: roberto.reyes@cnmh.gov.co
} 
Keywords: Memory, narratives, repair, therapy.

\section{Introducción}

En Colombia, desde el origen de su constitución como Estado soberano, han existido diferentes comisiones $y$ organizaciones de personas y entidades que han pretendido dar una explicación a los orígenes del conflicto, sus factores impulsores y los que han permitido que se haya eternizado y enquistado el conflicto en la esencia misma del colombiano. Algunas de estas son la Comisión Investigadora de las Causas de la Violencia, creada por el general Rojas Pinilla en 1958, cuyo propósito principal era encontrar las causas de la violencia e intervenirlas; - la Comisión de Estudios sobre la Violencia, en 1987, creada durante el gobierno de Virgilio Barco, que, además de tener un sentido más académico que político, arrojó como resultado el informe denominado "Colombia, Violencia y Democracia". En 1991, y producto de las desmovilizaciones del EPL y del Movimiento Quintín Lame, surgió la Comisión de Superación de la Violencia, cuyo resultado final es el informe "Pacificar la Paz", en el que ya se empieza a mencionar el paramilitarismo como fenómeno de violencia en el país (Rincón, 2016).

Otra de las comisiones creadas en el siglo pasado en Colombia fue la Comisión de Derechos Humanos de la Costa Atlántica, que resultó como parte de los acuerdos establecidos luego de las negociaciones de paz entre el Gobierno nacional y el Partido Revolucionario de los Trabajadores (PRT). El mayor logro de esta comisión fue el de acompañar el proceso de reinserción, además de estudiar la problemática de derechos humanos de la zona e integrar las organizaciones de derechos humanos junto con algunas organizaciones del Estado, como la Consejería Presidencial para los Derechos Humanos y la Participación, responsable de la reinserción de los excombatientes del PRT.

En 1994, luego de los acuerdos de paz entre el Gobierno nacional y la Corriente de Renovación Socialista, se crea la Comisión Nacional de Derechos Humanos, gracias a la cual se abrió el debate acerca de las reconocidas zonas de orden público, de la reforma penal militar y, más profundamente, de la problemática de derechos humanos en el territorio nacional (United Nations Peacemaker, 1994).

\footnotetext{
${ }^{3}$ Además de haber sido asesora de la Dirección General del Centro Nacional de Memoria Histórica, es la única mujer invitada a formar parte de la Comisión Histórica del Conflicto. Ha sido una estudiosa del conflicto armado, desde su papel en el CNMH y anteriormente en el Grupo de Memoria Histórica de la Comisión Nacional de Reparación y Reconciliación, así como docente de diferentes universidades del país. ${ }^{4}$ (1944-2019) Hizo parte de la Comisión de Esclarecimiento de la Verdad. Este sociólogo ha hecho aportes importantes a la comprensión del fenómeno de la violencia en Colombia, desde sus múltiples escritos, como desde la academia y su participación en diferentes espacios de opinión.
}

Una de las últimas comisiones creadas, posterior a otras comisiones incidentales creadas para casos específicos, como las de Trujillo, en el Valle del Cauca, o la de Barrancabermeja, en Santander, es la Comisión Nacional de Reparación y Reconciliación (CNRR), que surge de la Ley 975 o Ley de Justicia y Paz. Pese a tener una enorme participación del Gobierno de la época, contaba también con la participación de miembros de la sociedad civil, lo que no le valió para evadir las muchas críticas que tuvo, por su carácter aparentemente gobiernista y muy poco garante de los derechos de las víctimas, que era fundamentalmente su razón de ser (Menéndez, 2017).

Finalmente, y como parte de las negociaciones de paz en La Habana (Cuba), adelantadas entre 2012 y 2016 por el Gobierno colombiano y la guerrilla de las Farc, surgió la necesidad de conformar una comisión que diera cuenta de los orígenes del conflicto armado en el país: la Comisión Histórica del Conflicto y sus Víctimas, que tenía la misión de dar una explicación y, por lo menos, aventurarse a encontrar la razón de ser del conflicto, identificando algunos de los factores que llevaron a que diferentes agrupaciones se armaran y se mantuvieran alrededor de alguna causa en pugna con otro colectivo de personas en iguales circunstancias. Sin embargo, este intento por dar explicaciones al respecto no rindió frutos, ya que los diferentes académicos invitados a este interesante ejercicio presentaron lo que consideraron como elementos gestantes de lo que podría ser "quizá" nuestra más representativa característica en el ámbito mundial: ser el país con la guerrilla (recientemente desmovilizada) más antigua del hemisferio sur y con el conflicto armado más perdurable en el ámbito mundial.

De este ejercicio académico surgieron planteamientos interesantes y casi de obligatoria inclusión, como los de académicos y estudiosos del conflicto del nivel de María Emma Wills ${ }^{3}$, Alfredo Molano ${ }^{4}$, Gustavo Duncan ${ }^{5}$ o Eduardo Pizarro León Gómez ${ }^{6}$, quienes desde su propia postura, proponen un origen que radica en intereses políticos y económicos en los que aparecen elementos como las exclusiones, las marginaciones y la pobreza, y en los que los intereses de quienes ostentaban el poder frente a colectivos de personas en una clara desventaja

\footnotetext{
${ }^{5}$ Gustavo Duncan se dio a conocer por sus escritos acerca de narcotráfico, conflicto armado y la relación entre criminalidad y construcción de Estado. En sus escritos deja ver su posición acerca de la construcción de órdenes políticos alternos al Estado.

${ }^{6}$ Fue presidente de la Comisión Nacional de Reparación y Reconciliación, desde donde lideró los diferentes procesos de comprensión del fenómeno del conflicto armado, como respuesta a lo propuesto en la Ley 975 o Ley de Justicia y Paz. Ha sido académico y consultor permanente de temas relacionados con víctimas y conflicto armado. Integró la junta directiva del Fondo para las Víctimas de la Corte Penal Internacional.
} 
social llevaron a que se cocieran internamente las condiciones para una sublevación y una lucha por el poder y el statu quo. Es decir, es claro que los factores que generaron no solo las condiciones para el surgimiento del conflicto sino también su consistencia en el tiempo es eminentemente internos y obedecen a unas condiciones sociales propias de comunidades históricamente marginadas de la construcción de su propio futuro.

Sin embargo, también encontramos otras posturas diferentes, en las que se propone que la razón de ser de nuestro conflicto obedece a elementos exógenos que se mezclaron con nuestros propios factores, lo que dio como resultado la insubordinación de los pobres y de los inconformes. Aparecen entonces factores como el comunismo, el socialismo o los intereses de países como los Estados Unidos, que, según el investigador Renán $\mathrm{Vega}^{7}$, correspondían con una política norteamericana de protección de los estados de la insurgencia, resultante de la influencia cubana en todos los países al sur de México.

La última comisión creada con el propósito de esclarecer las causas y orígenes del conflicto es la que surge como producto de las negociaciones de paz en La Habana, y que es diferente a las comisiones anteriores: la Comisión de Esclarecimiento de la Verdad, la Convivencia y la No Repetición. Esta es más cercana en su misión a otras comisiones de la verdad del mundo, por su carácter no judicial y su labor de esclarecimiento tanto desde la voz de las víctimas como desde la de los otros actores que participaron en el conflicto armado.

A la par de estas entidades creadas con el fin de esclarecer las razones por las cuales tenemos enquistado en nuestra historia nacional el conflicto más largo del hemisferio, existen otras entidades que han intentado abordar el fenómeno del conflicto desde la memoria histórica. A partir de la Ley 1448 o Ley de Víctimas, y rescatando la experiencia surgida desde la Comisión Nacional de Reparación y Reconciliación, se crea el Centro Nacional de Memoria Histórica, que ha venido, a través de diferentes estrategias, conociendo cómo las comunidades construyen y reconstruyen su historia. Para este fin, han incluido y escuchado a todos los actores involucrados en el conflicto, con lo que han mostrado al país las experiencias de vida y de resistencia que han surgido después de las vivencias en la guerra.

A partir de ello, surgen dos rutas de análisis: la de las causas y la de los efectos. En cuanto a las causas, este ejercicio muestra un poco la imposibilidad de otorgar un origen único al conflicto, estableciendo no solo factores diversos, sino tiempos distintos. Seguramente, si se

\footnotetext{
${ }^{7}$ Este historiador, que tuvo que exiliarse del país durante un tiempo, por amenazas contra su vida, ha liderado desde la academia un movimiento interesante de estudio del conflicto y los elementos
}

consultara con varias personas de diferentes edades, e incluso en diferentes lugares del territorio nacional, se propondrían orígenes distintos y variados factores que harían imposible llegar al consenso.

En ese sentido, vemos que el conflicto no tiene un consenso frente a su origen, caso similar a lo que ocurre con sus efectos o consecuencias. Lira (2010) afirma en esa misma linea que cada sociedadg ha debido enfrentar el conflicto y sus consecuencias desde su historia y condiciones politicas, con los valores, principios y visiones politicas de su gente, con su capacidad de forjar dimensiones de responsabilidad compartida sobre el futuro, con el fin de detener la multiplicación de las víctimas y hacerse cargo de estas.

Por esto, se hace necesario encontrar formas y caminos para la reparación de todos los actores del conflicto (víctimas, actores armados, profesionales de atención a víctimas y excombatientes, etc.), a partir de sus distintas concepciones del trauma dejado por la guerra. Esto es, una reparación terapéutica y profunda que permita la reconstrucción de proyectos de vida fracturados por la presencia de la guerra en sus vidas y sus territorios. El trabajo terapéutico, sumado a la memoria y a la intervención psicosocial, forma parte fundamental de la reparación.

La misma Lira (2010) resalta el hecho de que:

[...] las pérdidas de vidas de personas queridas y el malogramiento de los proyectos personales tienen una dimensión irrecuperable y abrumadora en un contexto marcado por la impotencia de las víctimas ante los hechos consumados. El proceso terapéutico puede posibilitar reconocer el significado de lo vivido y rescatar lo reparable en un conjunto de experiencias vitales marcadas por lo irreparable.

Es entonces cuando surgen estrategias para reparar 10 dañado, a partir de la reconstrucción de significados. En este punto, la reparación se conecta con la construcción de memoria histórica, de tal suerte que la memoria no se convierte en simple hecho de recordar, sino de recordar con un sentido terapéutico.

En el ejercicio de la memoria, en la recuperación emocional y en la reparación de las víctimas, "lo importante no es lo que han hecho de nosotros, sino lo que hacemos con lo que han hecho de nosotros" (Sartre citado en Tognonato, 2001). Esto reafirma que la recuperación emocional de las personas afectadas por

generadores de este. Se hizo merecedor en el año 2008 del premio Libertador al Pensamiento Crítico. 
el conflicto, desde cualquiera de sus formas, depende en gran parte del afrontamiento que se haga de este, la agencia del dolor, el trámite de la afectación y los caminos disponibles para llegar al bienestar emocional después de la tormenta de la guerra.

En este sentido, en el presente artículo se reflexiona acerca del lugar que ocupa la memoria histórica en la reparación y en la ruta terapéutica por la que transitan los actores vinculados al conflicto que han participado en ejercicios de memoria adelantados por entidades como la Comisión Nacional de Reparación y Reconciliación y el Centro Nacional de Memoria Histórica, desde la experiencia psicosocial desarrollada por la Dirección de Acuerdos de la Verdad.

\section{Metodología}

Este documento es el resultado de los aprendizajes obtenidos del abordaje de la memoria de los diferentes actores involucrados. Se apoya en la revisión de investigaciones anteriores y escritos preliminares que presentan las implicaciones de la memoria en la recuperación emocional y psicológica de los participantes. Se utiliza la metodología de evaluación cualitativa, siguiendo el esquema de revisión documental, y se generan diferentes posturas y reflexiones críticas acerca de los efectos de la participación en ejercicios de memoria histórica, y cómo dichos efectos pueden llevar a un proceso reparador en los participantes (víctimas, excombatientes de grupos armados o profesionales que atienden dichas poblaciones).

\section{Las afectaciones de la guerra en víctimas y excombatientes}

Las afectaciones generadas por la guerra son tan variadas como actores vinculados a esta hay (directos o indirectos). Coinciden en el espectro del trauma psicosocial algunas afectaciones como el estrés postrauma, que aparece en casi todos los casos.

El problema de la salud mental debe ubicarse en el contexto histórico en donde cada individuo elabora y realiza su existencia en las telarañas de las relaciones (Martín-Baró, 1984). En ese sentido, no existe una diferencia en cuanto al rol cumplido dentro de la guerra, sino en las dimensiones de la afectación y en cómo afrontar dicho escenario de malestar psicológico y de trauma psicosocial.

${ }^{8}$ La Agencia para la Reincorporación y la Normalización (ARN) es una entidad del Estado colombiano que desde el 2011 surge como una unidad administrativa especial adscrita al Departamento Administrativo de la Presidencia de la Republica (DAPRE). En sus orígenes, la ARN se creó como el Programa para la Reincorporación de la Vida Civil (PRVC), y funcionaba adjunto al Ministerio del Interior y de Justicia entre el 2003 y el 2006, cuando se creó la Alta Consejería para la Reintegración
Según el informe de Salud Mental en el Contexto DDR, publicado por la Agencia para la Reincorporación y la Normalización (ARN) ${ }^{8}$ (Zapata y Aponte, 2018), y de acuerdo con las escalas calificadas con el modelo de Rasch ${ }^{9}$, el 30,9\% de la población desmovilizada presenta estrés postraumático; mientras que el $27,3 \%$, ansiedad, y el $4,1 \%$, consumo de sustancias alucinógenas.

Mientras que, basados en el documento Conpes 3554 de 2008 (Departamento Nacional de Planeación, 2008), los desmovilizados, en su mayoría, poseen atributos psicosociales y valores que limitan su posibilidad de interacción social. Dicho de otro modo, las personas desmovilizadas no cuentan con las suficientes competencias, o se encuentran muy afectadas como para enfrentar las demandas sociales de su entorno, lo que dificulta además la convivencia en el marco de la legalidad. El documento también afirma que estas mismas personas cuentan con unas características psicosociales particulares, resultantes de la interacción en contextos sociales, familiares, educativos, económicos y políticos, violentos o de exclusión, que han facilitado la inclusión de estas personas en la ilegalidad.

El caso de las víctimas no está muy alejado de esta realidad, ya que, en recientes estudios con víctimas del conflicto armado, los principales impactos psicológicos encontrados son trastornos de estrés postrauma, trastornos del estado de ánimo, ansiedad y depresión, fobias y consumo de sustancias; en particular, de alcohol (Aristizabal et al., 2012).

En cuanto a lo psicosocial, se han encontrado disminución de los niveles de calidad de vida, ruptura de redes sociales y afectivas, modificación de los roles familiares y desarraigo cultural, entre otras afectaciones (Alejo et al., 2007).

\section{El papel de la memoria histórica en la comprensión de nuestra realidad}

La memoria histórica y la construcción de realidad no son incompatibles (Bourdieu, 1999; Luckmann y Berger 1999; Ricoeur, 2010; Schutz, 1977). La construcción de realidad es un proceso de interacción activa en el que la interpretación de la realidad parte de la experiencia individual mediada por dos elementos fundamentales: la acción y la comunicación. Sin embargo, en esta díada se agrega un elemento adicional que, en un escenario como el colombiano, es fundamental. Se trata de la memoria

de Personas y Grupos Alzados en Armas, desde donde se acompañaron todos los procesos de DDR surgidos como parte de las desmovilizaciones individuales y colectivas de los grupos armados ilegales.

${ }^{9}$ El de Rasch es un modelo psicométrico utilizado para el análisis de datos categóricos como respuestas a preguntas en una cuestionario o evaluación que considera rasgos de personalidad, habilidades, actitudes y la posible dificultad del ítem. 
como catalizadora de la acción, que supone que todos estos procesos son sociales.

El construccionismo social, en uno de sus principios o características generales, propone la especificidad histórica y cultural en la que todos los sujetos que conocemos son productos social y culturalmente específicos. El elemento de construcción de significados conjuntos es fundamental, de tal manera que la realidad y la memoria histórica se encuentran en ese punto en el que lo simbólico y la realidad se construyen socialmente a partir de la experiencia. En un país como el nuestro, la experiencia es significativamente distinta en cada contexto.

Los relatos acerca de las historias de las personas que transitan de su condición de afectados hacia otra categoría de actor social se encuentran medianamente organizados alrededor de sus estrategias de afrontamiento. Es decir, a la par de las acciones que los llevaron a reconocerse como afectados por la guerra, también están las acciones que han adelantado para superarlas, de modo que la memoria no es solo la reconstrucción de sus experiencias traumáticas, sino también el recuento de sus estrategias para superar y afrontar el daño causado.

Dicho de otra manera, encontramos que el conflicto armado nos ha llevado a comprender y construir realidades distintas, toda vez que cada uno lo ha vivido de manera diferente. La experiencia de los excombatientes de cualquier organización armada tiene una visión considerablemente disímil de la que tienen las víctimas de cualquier hecho victimizante, lo que además le agrega un componente diferenciador en la ecuación, ya que existen diferencias significativas entre víctimas de violencia sexual en el marco del conflicto; víctimas de desplazamiento forzado, o sobrevivientes y familiares de víctimas de homicidio o de desaparición forzada solo por mencionar un par de casos-.

En esa misma cosmovisión de realidades, encontramos que la acción de cada uno de estos actores y la comunicación con la que han construido sus realidades terminan separándose cuando aparecen otros elementos, como la emocionalidad o los significados que se han construido alrededor del hecho, la víctima o el mismo victimario (se quisiera no hablar de víctimas o victimarios en este escrito, principalmente por la carga simbólica que esto trae al colectivo social colombiano).

En ese sentido, algunos autores como Samayoa (1990) afirman que los efectos de la violencia y la guerra no son un problema de individuos aislados, sino un problema estrictamente social. Para este autor, el daño producido no es solo el de la vida personal que se destruye, sino que el daño se ha causado a las estructuras sociales mismas, a las normas que rigen la convivencia, a las instituciones que regulan la vida de los ciudadanos, a los valores y principios con los que se ha educado.

De acuerdo con ello, la memoria como mecanismo para la reexperiencia de lo vivido es una reconstrucción individual y personal que se da en lo social. Es decir, la experiencia personal de la manera en que cada individuo vivenció los eventos ocurridos se elabora en el plano individual; pero los componentes y elementos que la conforman y la reconstrucción de dicha experiencia constituyen un ejercicio social en el que las emociones y significados construidos socialmente sirven como un catalizador de la experiencia. Los significados se construyen y se deconstruyen en el colectivo, lo que le permite al individuo otorgar al problema elementos de sentido e interpretación, a fin de comprender mucho mejor la experiencia.

Sin embargo, en la historia de los conflictos se han encontrado dos posturas respecto a la memoria histórica y la realidad. Por una parte, la del perdón y el olvido como mecanismo de reparación a partir del establecimiento de un punto final que permita a los actores vinculados con los hechos de violencia (como víctimas o como victimarios) asumir un punto límite de la experiencia, con lo que esta queda rezagada en la memoria, de modo que no genere malestar cuando se evoque. Esta postura asume que el olvido es impulsado por la necesidad humana de evitar el trauma y el dolor. Son innumerables los casos en los que se ha optado por el olvido como ejercicio para la eliminación de las experiencias traumáticas, casi como una respuesta instintiva y de carácter defensivo para evitar el sufrimiento, incluso por encima de las evidencias.

Por otra parte, se encuentra la postura de la memoria como herramienta de construcción de realidades $y$, en algunos casos, de su superación, que. consiste en recordar y no olvidar, o en recordar para aprender y superar. En cualquiera de los dos casos, la memoria se constituye como una herramienta fundamental para alimentar el recuerdo y otorgar atribuciones y significados.

En Chile, durante el proceso de reconstrucción posterior a la dictadura, se propusieron ejercicios de olvido bajo la premisa de que el olvido de los hechos de violencia podría ayudar a terminar con la fragmentación y ayudar en los procesos de reconciliación, tal como lo plantean Kovalskys y Lira (1996) en su libro Trauma social, lo que explicaría por qué en las últimas décadas se ha insistido en la estrategia de olvido como una suerte de terapia "sanadora".

Este fenómeno de olvido para evitar el trauma ha sido observado en otros conflictos en el ámbito mundial, y ha sido relatado por varios autores, como, por ejemplo, 
Samayoa (1990), que advierte la importancia del olvido como elemento cauterizador y sanador. Otros autores, como Ibañez (1989) o Ulloa (1999), hablan acerca de la función paralizadora del silencio, que, al "cancelar la palabra", cancela también la posibilidad de pensar en el pasado.

\section{La memoria histórica y su función reparadora}

Se han mencionado las dos posturas frente a la memoria y la construcción de realidad, la del recuerdo y la del olvido, esta última con el suficiente sustento teórico propuesto por diferentes autores en contextos de violencia a nivel de Latinoamérica. Sin embargo, si bien el olvido se ha propuesto como un mecanismo más para prevenir el trauma y el dolor que genera el recuerdo, quedan también claras las dificultades que esto trae para la superación del trauma: es un ejercicio de evitación mas no de superación. Como lo afirma Mier (1997), "ante el objeto que suscita dolor, que hace adivinable lo intolerable, el sujeto interpone el lenguaje como una forma de atenuar su virulencia, de construir una tolerancia que sabe ya un artificio".

En palabras de Wittgenstein (1975), la realidad es construida en el lenguaje; solo lo que puede ser expresado es lo que existe en nuestra realidad, de tal forma que al no nombrarlo no existe:

Si el lenguaje puede figurar la realidad es porque ambos pueden compartir la misma forma lógica. El concepto de proposición como figura lógica de la realidad implica tres elementos: a) el mundo (los hechos) como aspecto objetivo de la realidad figurativa, b) el lenguaje (las proposiciones) como su aspecto subjetivo y c) la forma lógica que media entre los dos. (Wittgenstein, 1975)

Ahora bien, en contraposición con esta postura, surgen iniciativas como la que existe actualmente en Colombia a través del Centro Nacional de Memoria Histórica ${ }^{10}$, que surge como una alternativa para contar lo ocurrido en el conflicto armado y, con ello, responder al derecho que tienen las víctimas a la verdad, pero también como una estrategia de no repetición de los hechos. Se cree que al contar y saber qué ocurrió en el conflicto armado colombiano, es posible aprender de lo sucedido para que no vuelva a ocurrir.

Este tipo de iniciativas responde no solo a una exigencia legal, sino que apunta también a un ejercicio terapéutico: la palabra como elemento sanador.

${ }^{10}$ El Centro Nacional de Memoria Histórica es una entidad de carácter oficial, aunque con independencia del Gobierno nacional, creada a partir de la Ley de Víctimas y Restitución de Tierras, y como continuación de la labor que ya venía realizando el Grupo de Memoria Histórica de la Comisión Nacional de Reparación y Reconciliación.
Como lo afirma Reyes (2016), en tanto nuestra realidad nos recuerde lo importante y significativa que es nuestra memoria para la vida y el futuro, se tendrá conciencia de lo que podremos hacer con ella, ya sea transformarla en memorias significativas, o en reencuentro, perdón y reconciliación.

A nivel institucional, entidades como el Centro Nacional de Memoria Histórica, y, a partir de los acuerdos de La Habana, la Comisión de la Verdad ${ }^{11}$ realizan la labor de recopilación de relatos, testimonios y evidencias del conflicto armado colombiano, desde la voz de los mismos actores, víctimas, victimarios, institucionalidad y sociedad civil, con el propósito de contar la verdad de lo sucedido; sin embargo, está claro que verdad y realidad no son lo mismo.

Se parte de la concepción lacaniana según la cual la realidad es el conjunto de elementos reales, mientras que lo real es el elemento básico de la realidad, lo que no resuelve el dilema de si la realidad es verdad o no (Lacan, 2007).

La labor de la memoria histórica apunta en principio a una verdad histórica, no a la realidad, ni a la que es construida simbólica o subjetivamente, sino a la que, de cierta manera, se llega objetivamente juntando relatos, vivencias y experiencias. Esto es, una realidad que se narra tal y como la expresa el actor que la vivió, sin ninguna interpretación. Pero ¿qué ocurre con la otra realidad, la de los significados, la de lo simbólico, esa que refleja la experiencia emocional de quienes vivieron el hecho violento?

Ahí es donde la memoria cambia de significado y aparecen sus implicaciones emocionales. Según Jelin (2003), lo que el pasado deja son huellas en las ruinas, y marcas materiales en las huellas mnémicas del sistema neurológico humano, en la dinámica psíquica de las personas en el mundo simbólico.

En ese sentido, la experiencia de memoria desde una iniciativa institucional es, por ende, una experiencia emocional, que lleva indefectiblemente al individuo que la experimenta a un viaje profundo por la emoción, el lenguaje, el recuerdo y la reexperiencia del evento y del hecho violento. Es decir, cuando una persona, en un proceso de reconstrucción de su historia de vida, nota las acciones que ha desarrollado posteriores a su experiencia traumática y los posibles resultados benéficos que estas acciones han generado, surge un importante efecto terapéutico (Molina Valencia, 2010).

\footnotetext{
"La Comisión de Esclarecimiento de la Verdad, la Convivencia y la No Repetición surge como parte de los acuerdos de La Habana entre el Gobierno colombiano y la guerrilla de las Farc, firmado el 24 de noviembre de 2016.
} 
Surgen entonces laboratorios de construcción de memoria sanadora, como el realizado por la Comisión de la Verdad, denominado "Verdad-Es que Sanan", en el que se trabaja la memoria desde elementos como el perdón, la comunicación apreciativa, las prácticas restaurativas y la memoria transformativa (Comisión de la Verdad, 2019); o el realizado en su momento por la Comisión Nacional de Reparación y Reconciliación ${ }^{12}$, en su trabajo de intervención psicosocial a víctimas en clave de reconciliación (Reyes, 2011), donde, a través de técnicas narrativas, se buscaba que las víctimas reconstruyeran su historia con un enfoque reparador y reconciliador.
Los efectos de este proceso no son visibles en el corto plazo, ya que, como se ha visto anteriormente, este es un proceso que implica tanto lo individual como lo colectivo, y en el que intervienen otros elementos, como lo social, lo simbólico, lo cultural e incluso lo lingüístico.

En ese sentido, es importante realizar un análisis desde lo que implica la conjugación de estos elementos, hasta llegar a un proceso transformador y reparador, tanto en la persona como en el colectivo.

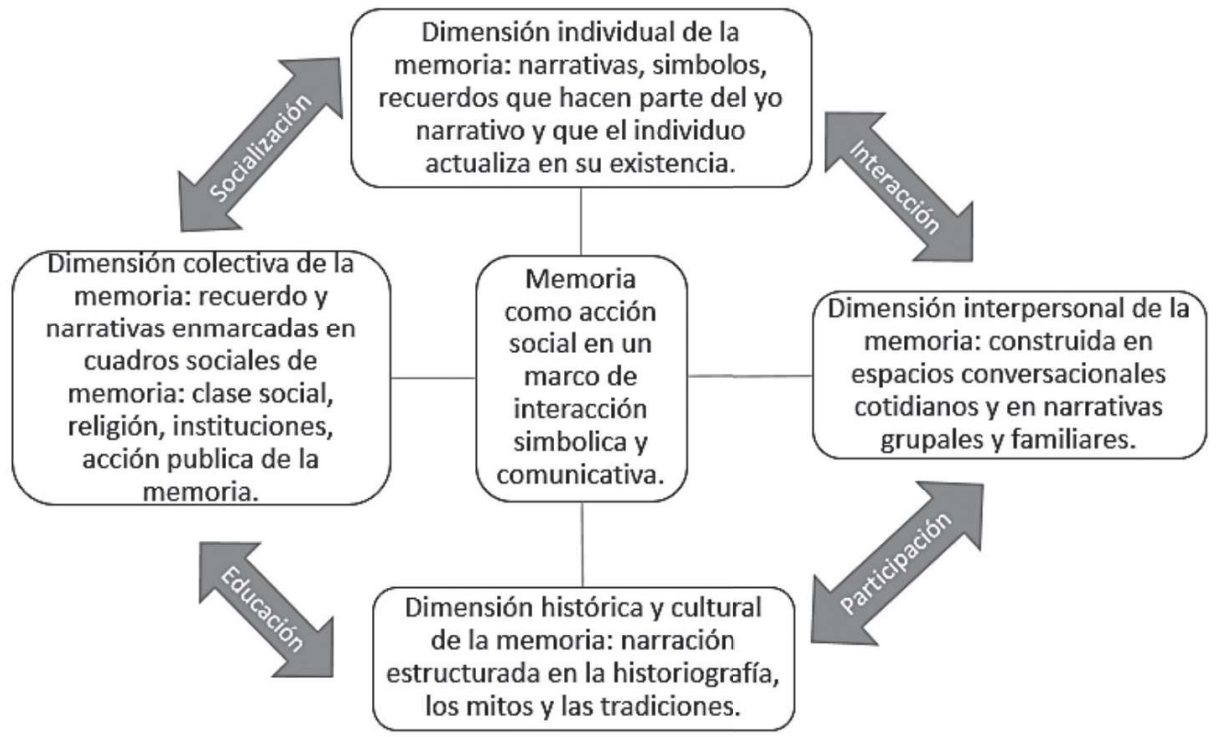

Figura 1. La función de la memoria. Fuente: Villa Gómez y Castrillon Baquero (2015).

En la Figura 1 se observa la relación existente entre las cuatro dimensiones en las que podría clasificarse la memoria, pasando de la memoria individual a la colectiva y las conexiones existentes entre la una y la otra. Se incorporan además los otros elementos mencionados en este artículo, como lo simbólico, la cultura, las narrativas y la acción social.

En ese sentido, es importante la comprensión de las principales dimensiones del esquema, con el fin de comprender, a su vez, las transformaciones que los procesos de memoria (individual y colectiva) generan en las personas y en su construcción personal y social.

Cada dimensión trae consigo unos elementos propios que se conectan con las otras dimensiones, a través de

${ }^{12}$ La Comisión Nacional de Reparación y Reconciliación fue una entidad de carácter oficial pero con carácter independiente, creada a partir de la Ley 975 o Ley de Justicia y Paz, con el propósito de acompañar a las víctimas en sus procesos de reclamación de derechos a verdad, justicia, reparación, reconciliación y no repetición, con presencia en todo el país y desde donde se adelantaron labores de acompañamiento e otros elementos como la socialización, la participación, la educación y la interacción. Todos y cada uno de esos elementos están en conexión permanente.

El concebir así la memoria nos ayuda a comprender la multidimensionalidad de la memoria y la interrelación entre cada elemento. De igual forma, encontramos lo propuesto en la Tabla 1, en la que las transformaciones generadas en procesos de memoria y apoyo mutuo se evidencian en tres dimensiones: la subjetiva, la interpersonal y la colectiva y social. Cada una propone distintas transformaciones vistas como efectos e impactos de la memoria en los sujetos y en el colectivo, así como en las interpretaciones que hacen de la realidad estos sujetos.

intervención a víctimas, así como liderar la política de reconciliación en el país y proponer estrategias para la garantía de derechos de las víctimas. El trabajo de reconciliación en la sede nororiente se enfocó en la construcción de identidades a través de las narrativas de reconciliación y reconocimiento de todos los actores del conflicto, con base en la estrategia de diálogos apreciativos y conversaciones públicas. 
Tabla 1

Transformaciones generadas en procesos de memoria compartida y apoyo mutuo $^{13}$

\begin{tabular}{|c|c|c|}
\hline $\begin{array}{l}\text { Dimensión } \\
\text { subjetiva }\end{array}$ & $\begin{array}{c}\text { Dimensión } \\
\text { interpersonal y } \\
\text { familiar }\end{array}$ & $\begin{array}{c}\text { Dimensión colectiva } \\
\text { y social }\end{array}$ \\
\hline $\begin{array}{l}\text { Transformación y } \\
\text { “curación" de } \\
\text { emociones } \\
\text { negativas }\end{array}$ & $\begin{array}{l}\text { Tramitación no } \\
\text { violenta de } \\
\text { conflictos } \\
\text { familiares }\end{array}$ & $\begin{array}{l}\text { Experiencia de } \\
\text { solidaridad a partir } \\
\text { de apoyo mutuo } \\
\text { Salida de la anomia }\end{array}$ \\
\hline $\begin{array}{l}\text { Elaboración de } \\
\text { duelo }\end{array}$ & $\begin{array}{l}\text { Buen trato a los } \\
\text { hijos }\end{array}$ & $\begin{array}{l}\text { Búsqueda de } \\
\text { espacios para apoyar }\end{array}$ \\
\hline $\begin{array}{l}\text { Recuperación del } \\
\text { sentido vital } \\
\text { Recuperación de la } \\
\text { dignidad }\end{array}$ & $\begin{array}{l}\text { Transformación } \\
\text { en los roles de } \\
\text { género. Las } \\
\text { mujeres asumen } \\
\text { lo público }\end{array}$ & $\begin{array}{l}\text { y ayudar } \\
\text { Demanda de } \\
\text { formación, } \\
\text { capacitación y } \\
\text { acompañamiento }\end{array}$ \\
\hline $\begin{array}{l}\text { Recuperación del } \\
\text { proyecto de vida }\end{array}$ & $\begin{array}{l}\text { Cambios en los } \\
\text { equilibrios de } \\
\text { las relaciones } \\
\text { con la pareja }\end{array}$ & $\begin{array}{l}\text { Surgimiento o } \\
\text { recuperación de } \\
\text { liderazgo }\end{array}$ \\
\hline $\begin{array}{l}\text { autoestima, de la } \\
\text { imagen positiva de } \\
\text { sí mismo y de las } \\
\text { creencias básicas }\end{array}$ & $\begin{array}{l}\text { Apertura y } \\
\text { recuperación de } \\
\text { relaciones } \\
\text { cotidianas }\end{array}$ & $\begin{array}{l}\text { Aumento de } \\
\text { cohesión social } \\
\text { construyendo } \\
\text { nuevas identidades }\end{array}$ \\
\hline
\end{tabular}

Fuente: Villa Gómez y Castrillon Baquero (2015).

Las implicaciones de esto radican en:

- Generación de formas de afrontamiento y resistencia individuales y colectivas.

- Empoderamiento de las víctimas a niveles individual y colectivo.

- Reconstrucción del tejido social.

A manera de conclusión, se interpreta que los procesos de memoria afectan al individuo en lo verbal, lo lúdico, lo social, lo relacional y lo interpersonal. Estas afectaciones o impactos se presentan en la Tabla 1, y entre ellas se destacan la curación de emociones negativas, la recuperación del sentido vital, la recuperación de la vida cotidiana o el aumento de cohesión social.

Ahora bien, no basta con la sola realización de ejercicios de memoria colectiva, sino que la memoria convertida en relato lleve a la acción transformadora; la memoria que al ser transformada, objetivada y sacada del mundo subjetivo es retornada en relato sanador; es decir, que no solo ayuda a quien emite el relato, sino a quien escucha.

${ }^{13}$ Tabla extraída del capítulo 9, "Efectos y procesos psicosociales alrededor de la memoria compartida (dimensión interpersonal y grupal de la memoria)", de la tesis doctoral denominada "El papel de la
Se modifica así la carga emocional del relato y de la memoria, y se le agregan nuevos elementos simbólicos que ayudan a elaborar la emoción: es el relato al servicio de la transformación, la memoria convertida en acción sanadora.

Según Maturana (1988), lo humano surge en la historia evolutiva del linaje homínido al que pertenecemos, al surgir el lenguaje. Además, este autor afirma, acerca de las realidades, que:

La existencia humana en el lenguaje configura muchos dominios de realidad, cada uno constituido como un dominio de coherencias operacionales explicativas. Estos distintos dominios de realidad son también dominios de quehacer que generamos en la convivencia con el otro y que, como redes de conversaciones (redes de coordinaciones de acciones y emociones), constituyen todos nuestros ámbitos, modos y sistemas (instituciones) de existencia humana. En estas circunstancias la realidad es una proposición explicativa de la experiencia humana.

En relación con la conexión existente entre la narrativa, la memoria y los significados, la manera en la que le otorgamos sentido y significados al relato es entonces mediante lo colectivo. Es por eso que, si bien nuestros recuerdos son individuales, los sentidos y significados se construyen socialmente; es decir, la narrativa de cada evento requiere incorporar las relaciones entre los personajes que hacen parte de dicho evento. El significado de cada uno de esos personajes le agrega nuevos elementos emocionales a la memoria, lo que, por supuesto, la dota de elementos significativos para la experiencia de vida del individuo.

\section{La terapia narrativa o la palabra como terapia}

Toda persona tiene una historia que contar, una experiencia de vida que se vuelve significativa. Cada vez que se cuenta esta experiencia, se le agregan nuevos elementos simbólicos y emocionales, lo que hace que nunca un relato sea el mismo. La narrativa crece o decrece en la medida en que se narra y se resignifica.

Gergen y Kaye (1996), al respecto, resaltan la importancia del otro en la atribución de significados a la narrativa en terapia. Dicho relato se aloja en alguno de los dominios de existencia en los que nos desenvolvemos, de tal forma que es con esos otros con los que se establece una organización coconstruida de significados. De esta manera, se conforma su realidad.

memoria colectiva en la reconstrucción del tejido social" (Villa Gómez y Castrillón Baquero, 2015). 
Así siempre es la historia difícil, desconcertante, dolorosa o iracunda de una vida o de una relación ya arruinada. Para muchos se trata de una historia de hechos calamitosos que conspiran contra su sensación de bienestar, de autosatisfacción, de eficacia. Para otros, la historia suele aludir a fuerzas invisibles y misteriosas que se introducen en las organizadas secuencias de la vida para perturbar y destruir. Y para algunos es como si en su ilusión de saber cómo es, cómo debería ser el mundo, hubieran tropezado con dificultades para las que su relato preferido no los había preparado. (Gergen y Kaye, 1996)

De acuerdo con ello, el ejercicio terapéutico de la memoria va entonces asociado no solo a lo que se dice, sino a todos los elementos simbólicos y de significados que se le otorgan al relato, y que le agregan, además, comprensión de contexto. Es preciso entender que no se trata de un relato en sí mismo, sino de un entramado de significados y simbolismos que se han construido socialmente, en el que tiene lugar la experiencia individual y fluctúa la vida subjetiva.

La labor terapéutica le exige entonces al terapeuta una misión semiótica adicional: la de leer más allá de lo que se dice, esto es, la de leer la memoria y la narrativa. Ya no es solo lo que se dice, sino lo que no se dice, lo que queda entredicho y lo que está detrás de lo que se dice: las emociones, el universo simbólico y la experiencia social en la que se encuentra el individuo.

Imaginar al individuo en la acción, ubicado en ese escenario simbólico y existencial en el cual el dolor o el trauma se generó, es un reto importante para el terapeuta. Por esta razón, la experiencia de transformación del relato es en sí misma un viaje al universo de la memoria simbólica, individual y construida en lo social. Esto es, la memoria de los sentidos, la de la emoción.

\section{Conclusiones y comentarios}

Un proceso de memoria histórica implica una transformación del recuerdo, su resignificación. Cuando este recuerdo es doloroso o impactante, el reconstruir este recuerdo y dotarlo de nuevos significados es, en ocasiones, el recurso que más a mano tienen todos y cada uno de los actores del conflicto. Sin embargo, es mayor el impacto de este recurso cuando se orienta con ese fin, y no solo con el propósito de recuperar una historia en particular.

Dicho de otra manera, un recuerdo nunca se recrea dos veces de la misma manera: siempre se le agregan o se le cambian atributos, lo que conduce el recuerdo por nuevas rutas, casi como un recurso heurístico que le permite a la persona reexperimentar el recuerdo de una manera distinta. Esto permite no solo una reelaboración de este, sino además la recuperación emocional de la persona, de una manera más reparadora e incluso propiciando un eventual proceso de reconciliación futuro.

Desarrollar entonces ejercicios de memoria histórica en clave de reparación es para el país una estrategia que serviría no solo para la reconstrucción, en este caso de la memoria histórica del conflicto, sino para la recuperación emocional de los participantes en dichos ejercicios de memoria. Al recuperar la memoria, se recupera la vida.

La narrativa como terapia -en la línea de autores como Sluzki (1992)-, utilizada en principio en la terapia familiar sistémica, abre la discusión acerca de la realidad y la construcción de la realidad. Esta narrativa le permite a la persona participante objetivar la realidad, dar forma, sentido y significados a lo que habita en su mente en forma de recuerdos, utilizando diferentes recursos lingüísticos, como la metáfora, las descripciones o las analogías, con el propósito de ver los hechos pasados de una manera distinta. Esto es, con el propósito de situar los hechos en una perspectiva diferente, lo que conduce a que cambie también la carga emocional que acompaña el relato.

La experiencia mundial de posguerra o de posdictadura ha sido la de punto final o experiencias de perdón y olvido; sin embargo, lo ocurrido en eventos como la atención a víctimas supervivientes de la Segunda Guerra Mundial se ha concentrado en el recuerdo como estrategia para la recuperación emocional de las víctimas, proporcionando recursos de ayuda, a través de grupos de autoayuda o de estrategias narrativas y de literatura, desde las cuales las víctimas reelaboran su experiencia, de forma que les permite expresarse a manera de válvula de liberación y catarsis. No fueron suficientes los juicios de Núremberg, donde los principales líderes nazis contaron su versión de los hechos: era necesario que las víctimas participaran de manera activa en la reconstrucción de la historia.

En Colombia, la memoria histórica ha sido utilizada en cumplimiento del derecho a la verdad; sin embargo, tal y como lo veíamos en la literatura explorada y en la revisión bibliográfica, la verdad es relativa. Una cosa es la verdad jurídica, que busca el cumplimiento de la ley, y otra es la verdad histórica, que se construye de forma individual, de acuerdo con la experiencia personal, y que cambia cada vez que se reelabora. En todos los ejercicios de memoria explorados, las víctimas refieren cómo narrar su experiencia de dolor los libera, les permite descargar su peso y compartirlo con otros.

La memoria histórica, entonces, se puede presentar de diferentes maneras, de acuerdo con cada persona y con cada experiencia. Se presenta desde expresiones escritas, 
orales, musicales y artísticas, y, en general, cualquier expresión que permita liberar el recuerdo y convertirlo en una nueva vivencia, con una carga emocional distinta. Cuanto más se exprese, más se transforma, hasta que logre ser objetivada. Bien lo han dicho muchas de las víctimas del conflicto armado en Colombia: "El olvido es otra forma de morir".

\section{Referencias}

Alejo, E., Rueda, G., Ortega, M. y Orozco, L. (2007). Estudio epidemiológico del TEPT en población desplazada por la violencia política en Colombia. Universitas Psychologica, 6(3), 623-635.

Aristizabal, E., Palacio, J., Madariaga, C., Osman, H., Parra, L., Rodriguez, J. y Lopez, G. (2012). Síntomas y traumatismo psíquico en víctimas y victimarios del conflicto. Psicología desde el Caribe, 29(1), 123-152.

Bourdieu, P. (1999). La miseria del mundo. Ediciones Akal.

Comisión de la Verdad. (2019). El poder sanador de la verdad. https://comisiondelaverdad.co/actualidad/noticias/ verdades-que-sanan?fbclid=IwAR3ialoUxdArA_ b16Z9K2BUuW8eURIUGv1TLhkdM6SqOYjXoSF8q oQnq_hw

Departamento Nacional de Planeación. (2008). Documento CONPES 3554. Política Nacional de Reintegración Social y Económica para Personas y Grupos Armados Ilegales. Bogotá. https://www.reincorporacion.gov. co/es/la-reintegracion/centro-de-documentacion/ Documentos/Documento Conpes 3554 I Política nacional de reintegración social y económica para personas y grupos armados ilegales.pdf

Gergen, K. y Kaye, J. (1996). La terapia como construcción social. Paidós.

Ibañez, T. (1989). Some Critical Comments About the Theory of Social Representations. Discussion of Räty \& Snellman. Ongoing Production on Social Representations, 1, 21-26.

Jelin, E. (2003). Los trabajos de la memoria. Siglo XXI.

Kovalskys, J. y Lira, E. (1996). Trauma Social. En E. Lira e I. Piper (eds.), Reparación, Derechos Humanos y Salud (pp. 23-56). CESOC.

Lacan, J. (2007). Lo simbólico, lo imaginario y lo real. In De los nombres del padre. Paidós.

Lira, E. (2010). Trauma, duelo, reparación y memoria. Revista de Estudios Sociales, (36), 14-28.

Luckmann, T. y Berger, P. (1999). La Construcción Social de la Realidad. Amorrortu Editores.

Martín-Baró, I. (1984). Guerra y salud mental. Estudios Centroamericanos, 429(430), 503-514.

Maturana, H. (1988). Lenguaje y realidad: El origen de lo humano. Conferencia organizada por la Sociedad de Biología de Chile. Club de Providencia, Santiago de Chile.

Menéndez, R. (2017). La participación de la sociedad civil en la construcción de la paz. ORBIS, 21, 14-19.

Mier, R. (1997). Schreber: introspección, negación, delirio.
Tramas II: Subjetividad y Procesos Sociales, 11, 55-63.

Molina Valencia, N. (2010). Reconstrucción de memoria en historias de vida. Efectos políticos y terapéuticos. Revista de Estudios Sociales, (36), 64-75. https://doi. org/10.7440/res36.2010.06

Reyes, G. (2011). Intervención psicosocial a víctimas en clave de reconciliación. Bucaramanga: CNRR.

Reyes, G. (2016). Paz, memoria y significados conjuntos. En COLPSIC, Separata: Trabajando por la paz y reconciliación. https://issuu.com/colpsic/docs/separata_ trabajando_en_la_paz_y_rec

Ricoeur, P. (2010). La memoria, la historia y el olvido. México. Rincón, M. C. (2016). Las lecciones de los "violentólogos" de 1987 para los de La Habana. https://pacifista.tv/ notas/29127-2/

Samayoa, J. (1990). Guerra y deshumanización: una perspectiva psicosocial. En I. Martín-Baró, Psicología social de la guerra (pp. 41-66). UCA Editores.

Schutz, A. L. (1977). Las estructuras del mundo de la vida. Amorrortu.

Sluzki, C. E. (1992). Transformations: A Blueprint for Narrative Changes in Therapy. Family Process, 31(3), 217-230.

Tognonato, C. (2001). Sartre contra Sartre. Ediciones del Signo.

Ulloa, F. (1999). Notas para una clínica de la crueldad. Clínica y Analísis Grupal, 80, 33-42.

United Nations Peacemaker. (1994). Acuerdo Político Final Gobierno Nacional Corriente de Renovación Socialista (CRS). https://peacemaker.un.org/colombiaacuerdopoliticocrs 94

Villa Gómez, J. D. y Castrillon Baquero, J. E. (2015). Procesos de memoria colectiva como dinámica psicosocial y sociopolítica en tres escenarios de organizaciones de mujeres: AMOR, PROVISAME, y el grupo de mujeres "Madres de La Candelaria", de la ciudad de Medellín. Presentado en Cátedra Unesco y Cátedra Infancia. Justicia Transicional y memoria histórica, Universidad Externado de Colombia. Universidad Externado de Colombia. https://doi.org/10.4000/books.uec.906

Wittgenstein, L. (1975). Tractatus Logico-Philosophicus. Alianza Universidad.

Zapata, J. G. y Aponte, D. M. (2018). Salud Mental en el Contexto DDR: Trayectoria, espectros de sufrimiento y calidad de vida en población desmovilizada del conflicto armado colombiano. Universidad Externado de Colombia. 